\title{
ANALISIS PENGARUH UKURAN PERUSAHAN, BOOK-TO-MARKET VALUE, DAN BETA TERHADAP RETURN SAHAM DI BEI
}

\author{
Hadi I smanto \\ STIENU Jepara
}

\begin{abstract}
Banyak perdebatan yang terjadi di dunia akademis dalam menguji CAPM. Menurut Fama dan French Size merupakan faktor penting dalam penjelasan perbedaan return, dan antara beta $(\beta)$ dan expected return tidaklah terdapat hubungan positif melainkan tidak berpola/tidak berhubungan. Tujuan penelitian ini adalah untuk membuktikan bahwa ukuran perusahan, book-to-market value, dan beta dapat mempengaruhi return saham di Bursa Efek Indonesia. Penelitian ini menggunakan data sekunder tentang harga saham bulanan dan data SBI tahun 2008-2010, pembentukan portofolio dengan menggunakan model fama dan french serta model empiris Michael E. Drew dan Madhu Veeraraghavan dan menggunakan regresi linier untuk menganalisis data. Hasil dari penelitian ini memberikan bukti empiris bahwa beta secara individu mempengaruhi return saham dalam semua portofolio yang di bentuk. Sedangkan beta dan size secara individu mempengaruhi return saham hanya dalam portofolio yang dibentuk berdasarkan kategori pengelompokan saham, yaitu BL dan BH. Sedangkan beta, size, dan BMV secara bersama-sama tidak mempengaruhi return saham pada semua variabel return portofolio.
\end{abstract}

Kata kunci: Return, Beta, Size,dan rasio book-to-market value

\section{A. Pendahuluan}

Keputusan investasi merupakan salah satu hal paling penting yang dihadapi investor, keputusan investasi bagi seorang investor menyangkut masa akan datang yang mengandung ketidakpastian, atau mengandung unsur risiko bagi investor. Keinginan mendapatkan keuntungan merupakan suatu harapan bagi semua investor. Semakin tinggi risiko (risk) yang dihadapi seorang investor, semakin tinggi pula harapan investor untuk mendapat keuntungan (expected return).

Pendapatan (Return) merupakan salah satu faktor yang dapat mempengaruhi investor dalam menanamkan modalnya. Return total dapat diperoleh dengan menjumlahkan yield dan capital gain (loss), di mana yield merupakan komponen return yang mencerminkan aliran kas atau pendapatan yang diperoleh secara periodik dari suatu investasi. Sedangkan capital gain (loss) merupakan kenaikan (penurunan) harga suatu surat berharga, yang bisa memberikan keuntungan (kerugian) bagi investor (Tandelilin, 2001). 
Expected return dapat diperoleh dengan menggunakan single factor model yang biasa disebut dengan Capital Asset Pricing Model (CAPM) dan model tiga faktor yang diajukan oleh Fama dan French. CAPM menjelaskan keseimbangan pasar antara tingkat risiko yang sistematis dan tingkat keuntungan yang disyaratkan sekuritas portofolio. Dengan kata lain tujuan utama penggunaan CAPM adalah untuk menentukan tingkat keuntungan minimum yang disyaratkan dari suatu investasi. Keseimbangan pasar menurut kriteria markowitz menegaskan dua hal; (i) hubungan positif antara expected return $(\mathrm{E}(\mathrm{r})$ ) dan Beta, (ii) Beta sebagai pengukur risiko tunggal, sebagai penjelas adanya perbedaan $\mathrm{E}(\mathrm{r})$ antar saham (cross section), artinya kita dapat menggunakan beta untuk mengetahui risiko serta untuk mengetahui $E(r)$ suatu saham.

Sejak pertama kali diperkenalkan sampai saat ini, pengujian terhadap CAPM terus dilakukan. Pengujian pertama dilakukan oleh Lintner yang memberikan hasil yang tidak mendukung CAPM (Husnan, 2003). Selain itu Miller juga mengkritik tentang asumsi CAPM yang menyatakan homogeneous expectation antara para investor. Miller (1977) menyatakan perdagangan dapat terjadi karena adanya heterogeneous expectation dengan kata lain perdagangan terjadi disebabkan oleh "sebagian kecil" investor memiliki sikap optimis (Asnawi dan C. Wijaya, 2005).

Selain itu masih banyak perdebatan yang terjadi di dunia akademis Jagannathan dan McGrattan dalam artikelnya menyebutkan beberapa tokoh akademis yang menguji CAPM ini di antaranya Fama dan French (1992) yang menyebutkan bahwa beta tidak satu-satunya yang dapat menjelaskan cross-section variation dalam return, tetapi size dan book-to-market equity juga yang lebih penting.

Kothari, Shanken, dan Sloan (1995) berpendapat tentang penemuan Fama dan French (1992) tergantung bagaimana orang menginterpretasikan tes statistiknya. Kothari, Shanken, dan Sloan berfokus pada estimasi koefisien beta yang diajukan Fama dan Frenh, mereka berpendapat estimasi tersebut mempunyai standar error yang tinggi dan itu berimplikasi pada jauhnya range risk premium.

Berdasarkan uraian di atas, maka dapat diambil suatu rumusan masalah sebagai berikut; apakah ukuran perusahan, book-to-market value, dan beta dapat mempengaruhi return saham di Bursa Efek Indonesia? Sehingga tujuan penelitian yang dilakukan penulis adalah bertujuan untuk membuktikan apakah ukuran perusahan, book-to-market value, dan beta dapat mempengaruhi return saham di Bursa Efek Indonesia.

Return atau tingkat keuntungan dari investasi merupakan hal yang penting bagi pemodal. Bagi para pemodal return merupakan tujuan dalam berinvestasi, karena alasan utama orang berinvestasi adalah untuk memperoleh keuntungan. Return yang 
diharapkan investor dari investasi yang dilakukannya merupakan kompensasi atas biaya kesempatan (opportunity cost) dan risiko penurunan daya beli akibat adanya pengaruh inflasi. Sehingga return akan sangat krusial bagi para pemodal dalam melakukan investasinya.

Dalam melakukan investasi, investor akan memperkirakan berapa tingkat pendapatan yang diharapkan (expected return) dalam suatu periode tertentu di masa datang. Namun, pendapatan yang diterima (actual return) belum tentu sama dengan yang diharapkan. Untuk itu investor harus selalu mempertimbangkan ketidakpastian tersebut yang merupakan risiko investasi. Risiko menunjukkan penyimpangan antara pendapatan yang diterima dengan pendapatan yang diharapkan. Menurut Brigham dan Daves (2004), risiko adalah kemungkinan keuntungan yang diterima lebih kecil dari pada keuntungan yang diharapkan. Sedangkan menurut Jones (2004), risiko adalah kemungkinan pendapatan yang diterima (actual return) dalam suatu investasi akan berbeda dengan pendapatan yang diharapkan (expected return).

Menurut Jones (2004) return investasi terdiri dari dua komponen utama, yaitu yield dan capital gain (loss). Yield merupakan komponen return yang mencerminkan aliran kas atau pendapatan yang diperoleh secara periodik dari suatu investasi. Sedangkan capital gain (loss) sebagai komponen kedua dari return merupakan kenaikan (penurunan) harga suatu surat berharga yang bisa memberikan keuntungan (kerugian) bagi investor. Dengan kata lain capital gain (loss) dapat diartikan sebagai perubahan harga sekuritas. Berdasarkan komponen return yang sudah disebut sebelumnya, maka akan didapat return total yang merupakan salah satu pengukuran return realisasi, secara matematis return total dapat diltuliskan sebagai berikut:

Return total $=$ yield + Perubahan harga

Di mana: - Yield hanya akan berupa angka nol (0) dan positif $(+)$

- Perubahan harga bisa berupa angka minus $(-)$, nol $(0)$ dan positif $(+)$

Seperti dijelaskan di atas, di samping investor akan memperhitungkan return sebagai hasil investasi, investor juga harus selalu mempertimbangkan ketidakpastian investasinya yang merupakan risiko investasi. Risiko merupakan kemungkinan perbedaan antara return aktual yang diterima dengan return yang diharapkan. Semakin besar kemungkinan perbedaannya, berarti semakin besar risiko investasi tersebut. Ada beberapa sumber risiko yang dapat mempengaruhi besar kecilnya risiko suatu investasi antara lain: Risiko suku bunga, Risiko pasar, Risiko inflasi, Risiko bisnis, Risiko finansial, Risiko likuiditas, Risiko nilai tukar mata uang, dan Risiko negara (country risk). 
Di samping beberapa sumber risiko di atas, investor juga perlu memperhatikan tipe dari risiko tersebut. Ada dua tipe risiko, yaitu:

1. Risiko sistematis

Merupakan risiko yang disebabkan oleh berbagai faktor makro dan mempengaruhi semua perusahaan atau industri. Resiko sistematis tidak dapat dihilangkan walaupun dengan cara diversifikasi. Faktor-faktor makro yang dimaksud antara lain adalah perubahan suku bunga, melemahnya nilai tukar valuta asing, dan resesi ekonomi.

2. Risiko tidak sistematis

Merupakan resiko yang disebabkan oleh faktor-faktor mikro yang terdapat pada perusahaan atau industri tertentu, sehingga pengaruhnya hanya terbatas pada perusahaan atau industri tersebut, dan risiko ini dapat dihilangkan dengan cara diversifikasi. Faktor-faktor tersebut antara lain struktur aktiva, struktur modal, kondisi dan lingkungan kerja.

Model keseimbangan merupakan salah satu cara untuk menentukan pengukur risiko yang relevan dan bagaimana hubungan antara risiko untuk setiap aset apabila pasar modal dalam keadaan seimbang. Ada dua model keseimbangan yang biasa digunakan yaitu Capital Asset Pricing Model (CAPM) dan Arbitrage Pricing Model (APT).

Menurut Husnan (2003) CAPM merupakan model yang pertama kali dirumuskan sebelum berbagai asumsi yang mendasari dilonggarkan. Karena keadaan dunia nyata sangat kompleks maka model ini diperlukan penyederhanaan. Berbagai penyederhanaan tersebut ditunjukkan dari asumsi-asumsi yang dipergunakan untuk menyusun model tersebut. Asumsi-asumsi yang digunakan dalam CAPM adalah sebagai berikut:

1. Tidak ada biaya transaksi. Dengan demikian pemodal bisa membeli atau menjual sekuritas tanpa menanggung biaya transaksi.

2. Investasi sepenuhnya bisa dipecah-pecah (fully divisible). Artinya pemodal bia melakukan investasi sekecil apapun setiap jemis sekuritas.

3. Tidak ada pajak penghasilan bagi para pemodal. Dengan demikian pemodal akan merasa indifferent antara memperoleh dividen atau capital gains. Pemodal dikatakan memperoleh capital gains kalau terjadi kenaikan harga saham dan capital loss kalau terjadi penurunan harga saham.

4. Pemodal tidak mempengaruhi harga saham dengan tindakan membeli atau menjual saham. Asumsi ini analog dengan asumsi persaingan sempurna dalam teori ekonomi. Meskipun tidak ada pemodal individual yang bisa mempengaruhi harga, tindakan pemodal secara keseluruhan akan mempengaruhi harga. 
5. Para pemodal diasumsikan akan bertindak semata-mata atas pertimbangan expected value dengan deviasi standar tingkat keuntungan portofolio.

6. Para pemodal bisa melakukan short sale.

7. Terdapat riskless lending dan borrowing lending rate, sehingga pemodal bisa menyimpan dan meminjam dengan tingkat bunga yang sama.

8. Pemodal mempunyai pengharapan yang homogen. Ini berarti para pemodal sepakat tentang expected returns, deviasi standar, dan koefisien korelasi antar tingkat keuntungan.

9. Semua aktiva bisa diperjualbelikan

Asumsi-asumsi di atas merupakan bentuk penyederhanaan dari realitas yang ada, meskipun asumsi-asumsi tersebut tidak sesuai dengan keadaan nyata, tetapi yang perlu diingat adalah bukan realities tidaknya asumsi-asumsi tersebut, tetapi (1) sejauh mana realitas terdistorsi dengan asumsi-asumsi tersebut?, (2) mengarah ke mana asumsi-asumsi tersebut dalam menjelaskan pasar modal?, (3) apakah asumsi-asumsi tersebut tampak menjelaskan kinerja yang sebenarnya dari pasar modal? (Husnan, 2003).

Dalam CAPM ukuran risiko yang digunakan bukan lagi deviasi standar melainkan beta. Beta merupakan slope persamaan regresi antara return suatu saham dengan tingkat keuntungan portofolio pasar.

Persamaan matematis dari CAPM adalah:

$$
E\left(R_{i}\right)=R_{f}+\beta\left(R_{m}-R_{f}\right)
$$

Di mana:

$$
\begin{array}{ll}
E\left(R_{i}\right) & =\text { expected return saham i } \\
R_{f} & =\text { risk free asset } \\
R_{m} & =\text { return pasar } \\
\beta & =\text { beta }
\end{array}
$$

Di atas telah dijelaskan bahwa CAPM merupakan model yang menggambarkan keseimbangan pasar. Dalam pasar yang seimbang investor dapat menganalisis return yang diharapkan dan risiko yang akan didapat dengan menggunakan konsep capital market line (CML) di mana konsep ini menjelaskan hubungan keseimbangan antara return ekspektasi dan risiko total untuk diversifikasi portofolio yang efisien, dan konsep security market line (SML) di mana konsep ini menunjukkan hubungan keseimbangan antara return yang diharapkan dengan risiko sistematis. 
Hubungan yang ditunjukkan oleh Capital market line dapat dilihat pada gambar 1 berikut:

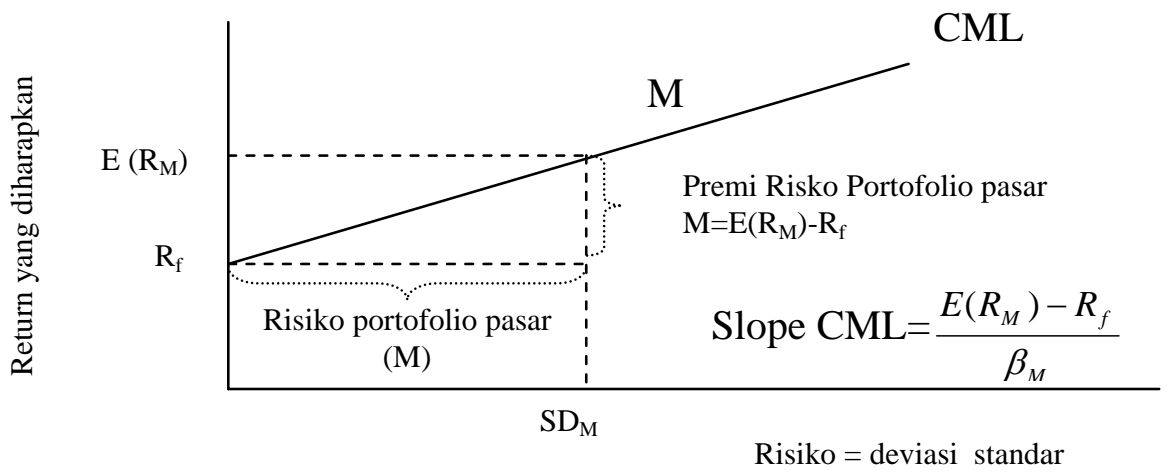

Gambar 1. Capital Market Line dan komponen slopes

Sumber: Jones (2004), Investments, Analysis and Management, hal.225

Dari gambar $1 \mathrm{di}$ atas, maka slope dari CML dapat ditulis sebagai berikut:

Slope dari $C M L=\left[E\left(R_{M}\right)-R_{F}\right] / \sigma_{M}$

Sehingga persamaan untuk CML dapat ditulis sebagai berikut:

$$
\mathrm{E}\left(\mathrm{R}_{\mathrm{P}}\right)=\mathrm{R}_{\mathrm{F}}+\frac{E\left(R_{M}\right)-R_{F}}{\sigma_{M}}
$$

Di mana:

$E\left(R_{P}\right)$ = return yang diharapkan dari setiap portofolio pada $C M L$

$\mathrm{R}_{\mathrm{F}} \quad=$ tingkat return pada risk-free rate

$E\left(R_{M}\right)$ = return yang diharapkan pada portofolio $M$

$\sigma_{\mathrm{M}} \quad=$ deviasi standar dari return pada portofolio pasar

$\sigma_{\mathrm{P}} \quad=$ deviasi standar dari portofolio efisien

Banz (1981) melakukan pengujian terhadap CAPM dengan meneliti apakah size perusahaan dapat menjelaskan residual variation dalam average return yang tidak dijelaskan oleh beta CAPM. Banz mengkritik CAPM dengan menunjukkan bahwa size dapat menjelaskan lebih baik dari beta tentang variasi cross-sectional dalam average return pada beberapa aset penting.

Banz (1981) menggunakan prosedur yang mirip dengan prosedur portofolio cara asset dibagi 5 subkelompok berdasarkan historical beta masing-masing asset, kemudian saham di setiap subkelompok dibagi 5 subkelompok lagi berdasarkan market value equity perusahaan, sehingga terdapat 25 portofolio. Portofolio tersebut 
di update setiap tahun di akhir tahun. Banz menggunakan NYSE dan mengestimasi hubungan cross-sectional antara return, beta, dan relative size.

Drew dan Madhu Veeraraghavan (2003) juga melakukan penelitian dengan menggunakan modelnya Fama dan French (1992) mereka membagi dua kelompok untuk size yaitu small dan big sedangkan untuk BMV dibagi ke dalam tiga kelompok yaitu low, medium, dan high, sehingga didapatkan 6 portofolio. Mereka melakukan pengujian di Hongkong, Korea, Malaysia, dan Philipina. Dari penelitian mereka disimpulkan bahwa beta bukan satu-satu variabel yang menjelaskan return bahkan tidak cukup menjelaskan cross-section dari expected return. Mereka menemukan bahwa ukuran perusahaan, dan book-to-market equity dapat secara signifikan menjelaskan return saham.

Model tiga faktor Fama dan French dibentuk dengan dilatarbelakangi untuk menguji model CAPM. Penelitian mereka diawali dari penelitian sebelumnya yang menemukan adanya faktor lain selain beta yang dapat mempengaruhi return saham. Penelitian-penelitian tersebut antara lain, adanya hubungan yang kuat antara beta dengan size suatu perusahaan, maka faktor size harus dipertimbangkan (Fama dan Macbeth, 1972) selanjutnya ditemukan juga hubungan yang kuat antara return saham, size dan rasio book-to-market value dari penelitian Banz (1981), Reinganum (1981), stattman (1980), Rosenberg, Rein, dan Lanstein (1985) dan Drew dan Veeraraghavan (2003). Adanya hubungan yang lemah return saham dan beta (Levy, 1978) dan Lakonishok dan Shapiro (1986). (dalam Manullang, 2001).

Fama dan French (1992) melakukan penelitian mengenai faktor size dan book-tomarket equity yang mempengaruhi return saham. Mereka menggunakan semua data return saham dari NYSE, AMEX dan NASDAQ, dengan periode tahun 1962-1989. Namun mereka tidak memasukkan perusahaan keuangan sebagai data dalam penelitian. Metodologi yang digunakan oleh Fama dan French di dalam menentukan nilai beta adalah identik dengan metodologi pada Fama dan Macbeth (1972), yaitu melakukan regresi cross-sectional dengan mengendalikan variable size dan rasio book-to-market sebagai cara untuk memilih sampel.

Untuk melakukan pengujian standard apakah variabel eksplanator berbeda pada harga rata-rata maka diperlukan hasil rata-rata time series dari kemiringan regresi bulanan. Fama dan French menemukan adanya kombinasi size dan book-to-market value dalam menangkap variasi cross-sectional pada return rata-rata yang dihubungkan dengan beta, sama baiknya seperti faktor-faktor pricing anomalous lainnya. Sedangkan hubungan beta dengan return rata-rata lemah pada saat pengujian yang dilakukan memasukkan variable beta yang tidak berhubungan dengan sizedecline pada 10 portofolio berbasis beta pre-ranking untuk saham individual. 
Kemudian ditentukan beta post-ranking-nya dari portofolio size-beta dalam akhir Juni tahun t. kesimpulan dari hasil penelitian Fama dan French (1992), adalah sebagai berikut:

1. Ketika Fama dan French memperbolehkan adanya variasi dalam beta yang tidak berhubungan dengan size, maka tidak ditemukan adanya hubungan yang meyakinkan antara beta dengan return rata-rata.

2. Peran berlawanan dari leverage pasar dan book leverage dalam return rata-rata dapat ditangkap dengan baik oleh book-to-market equity.

3. Hubungan antara E/P dan return rata-rata terlihat seperti terserap oleh kombinasi antara size dan book-to-market equity.

Kesimpulan di atas mengimplikasikan bahwa beta pasar terlihat seperti tidak mempunyai peran dalam menjelaskan return rata-rata pada saham NYSE, AMEX dan NASDAQ untuk periode 1963-1990, namun size dan book-to-market equity dapat menangkap variasi cross-sectional pada return saham rata-rata yang berhubungan dengan leverage dan $\mathrm{E} / \mathrm{P}$.

Fama dan French (1993), mengkonfirmasikan bahwa portofolio dibentuk dengan tujuan untuk menurunkan faktor risiko yang berhubungan dengan size dan market-tobook equity sehingga secara substansial dapat menambahkan variasi return saham yang dijelaskan oleh portofolio pasar. Fama dan French (1995) melakukan penelitian dengan tujuan untuk mengetahui apakah sifat harga saham dalam hubungannya dengan size dan market-to-book equity konsisten dengan sifat pendapatan. Sebagai langkah awal mereka meneliti apakah harga saham mencerminkan perbedaan dalam evolusi profitabilitas pada saat saham dikelompokkan menurut size dan market-tobook equity. Hasilnya, seperti yang telah diprediksi oleh model rational-pricing sederhana, market-to-book equity tinggi menandakan pendapatan rendah pada book equity, demikian juga sebaliknya, market-to-book equity rendah menandakan pendapatan tinggi pada book equity. Size juga berhubungan dengan profitabilitas, namun hubungannya berbanding lurus. Saham-saham kecil cenderung untuk memiliki pendapatan rendah pada book equity dibandingkan dengan saham-saham besar.

Dalam kaitannya dengan pengujian model tiga faktor Fama dan French, Daniel dan Titman (1997) menegaskan bahwa tiga faktor Fama dan French bukan struktur covariant return yang menjelaskan cross-section return saham. Mereka menjelaskan melalui "karakteristik model", berdasarkan pada expected return yang berhubungan secara langsung dengan karakteristiknya, seperti liquidity yang tidak mempunyai pengaruh dengan struktur covariant return. Lebih lanjut Daniel dan Titman mengamati hasil dari Fama dan French, ketika menguji seasonality effects, mengindikasikan 
bahwa size effect itu terjadi pada bulan januari, dimana efek BE/ME terjadi lebih besar di bulan Januari untuk perusahaan besar.

Sedangkan menurut Davis et.al (2000), Berk (2000) dan Pastor dan Stambaugh (2000) menemukan bukti yang mendukung Model Tiga faktor Fama dan French sekaligus menolak model karakteristik dasar Daniel dan Titman. Davis at.al (2000) melaporkan temuan bahwa sampel yang dipakai Daniel dan titman merupakan sample yang spesifik dan Model Tiga Faktor Fama dan French menguji sample jangka panjang pada U.S. stock return. Demikian juga Berk (2000) yang berargumen bahwa metodologi yang digunakan Daniel dan Titman (1997) salah, mereka merusak explanatory power dari asset pricing model dalam kelompok, kemudian tidak memasukkan fungsi Model Tiga Faktor Fama dan French. Pastor dan Stambaugh (2000) menjelaskan bahwa dua model tersebut masih dalam perdebatan, tetapi esensi dari kedua model tersebut mempunyai kemiripan.

Gregory Connor dan Sanjay Sehgal (2001) melakukan pengujian model Fama dan French terhadap saham yang ditransaksikan di India. Data yang digunakan adalah return saham bulanan dengan periode dari Juni 1988 sampai maret 1999. Mereka menguji hubungan faktor tunggal linier pricing yang diimplikasikan dengan CAPM yang kemudian dibandingkan dengan model tiga factor Fama dan French. Yaitu dengan menganalisis apakah market, size dan value factors dapat digunakan dalam crosssection saham secara acak. Selain itu dilakukan juga penelitian apakah market, size, dan value factors dalam pendapatan perusahaan mirip dengan return saham tersebut serta apakah faktor risiko umum dalam pendapatan dapat diterjemahkan ke dalam faktor risiko umum pada return saham. Hasil yang didapat secara umum memberikan bukti yang mendukung model Fama dan French. Faktor market, size, dan value dapat mempengaruhi return saham secara acak pada Indian Stock Market. Sehingga memberikan kesimpulan bahwa faktor tunggal CAPM dapat ditolak, sedangkan model Fama dan French tidak dapat ditolak. Ada beberapa bukti yang lemah untuk market, size, dan value factors dalam hubungannya dengan pendapatan, walaupun sampel yang digunakan sangat sedikit untuk dapat membuat pernyataan yang meyakinkan. Hasil lainnya adalah tidak ditemukannya bukti yang menunjukkan faktor risiko umum pada tingkat pertumbuhan pendapatan memiliki hubungan dengan return portofolio.

Kerangka pemikiran teoritis dalam penelitian ini adalah tentang perbedaan antara model Tiga Faktor Fama dan French dengan CAPM dalam menjelaskan return saham. Variable yang digunakan dalam penelitian ini adalah beta pasar, firm size, book to market ratio sebagai variable independen dan return saham sebagai variabel dependen. Hipotesis dalam penelitian ini adalah Beta dapat mempengaruhi return saham di Bursa Efek Indonesia; Beta dan Size dapat mempengaruhi return saham di 
Bursa Efek Indonesia; dan Beta, Size dan Book-to-Market Value dapat mempengaruhi return saham di Bursa Efek Indonesia.

\section{B. Metode Penelitian}

Data yang digunakan berupa data sekunder yang didapat dari Direktori Pasar Modal (DPM) UGM yang dikelola FE-UGM dan FE-UNDIP pada data harga saham bulanan dan data SBI tahun 2008-2010.

Jenis data yang digunakan dalam penelitian adalah:

1. Harga saham yang merupakan harga saham bulanan pada saat penutupan hari terakhir setiap bulan, dengan periode tahun 2008-2010.

2. Size, yaitu harga saham dikalikan jumlah saham beredar.

3. Rasio book-to-market value (BMV), yaitu book value of equity per share/market value of equity dengan:

a. Book value didefinisikan sebagai asset bersih (net asset) / jumlah saham yang beredar.

b. Market value (MV) didefinisikan sebagai harga saham dikalikan dengan jumlah saham biasa yang beredar.

4. Indeks LQ45 bulanan, yaitu: indeks pasar yang dikelola Bursa Efek Jakarta dan digunakan sebagai proxy portofolio pasar. Pada penelitian ini, diasumsikan bahwa proxy yang digunakan dapat mengidentifikasi portofolio pasar yang efisien.

5. Frekuensi perdagangan, yaitu: frekuensi dari saham yang diperdagangkan atau keaktifan suatu saham diperdagangkan pada pasar modal.

6. Tingkat return bulanan, yaitu: return suatu saham, yang merupakan: natural logaritma harga saham pada bulan $\mathrm{t}-1$ dibagi harga saham pada bulan $\mathrm{t}$.

Portofolio dibentuk dengan terlebih dahulu melakukan pengelompokan atas sampel berdasarkan fama dan french (1995), yakni:

1. Mengklasifikasikan saham berdasarkan rasio book-to-market menjadi tiga kelompok:

a. Kelompok saham yang memiliki rasio book to market tinggi, sebanyak $30 \%$ dari jumlah total saham yang dijadikan sampel.

b. Kelompok saham yang memiliki rasio book to market medium, sebanyak $40 \%$ dari jumlah total saham yang dijadikan sampel.

c. Kelompok saham yang memiliki rasio book to market rendah, sebanyak $30 \%$ dari jumlah total saham yang dijadikan sampel.

2. Mengklasifikasikan saham berdasarkan size menjadi dua kelompok, yaitu:

a. Kelompok saham yang memiliki kapitalisasi kecil.

b. Kelompok saham yang memiliki kapitalisasi besar. 
Setelah pengklasifikasian atas saham sudah dilakukan seperti yang sudah disebutkan sebelumnya, maka akan dibentuk enam portofolio setiap tahunnya, yaitu dengan menggunakan kombinasi atas saham yang sudah diklasifikasikan. Sehingga enam portofolio yang dibentuk adalah sebagai berikut:

1. Kelompok saham dengan book-to-market tinggi dan kelompok saham dengan kapitalisasi kecil

2. Kelompok saham dengan book-to-market tinggi dan kelompok saham dengan kapitalisasi besar.

3. Kelompok saham dengan book-to-market medium dan kelompok saham dengan kapitalisasi kecil.

4. Kelompok saham dengan book-to-market medium dan kelompok saham dengan kapitalisasi besar.

5. Kelompok saham dengan book-to-market rendah dan kelompok saham dengan kapitalisasi kecil.

6. Kelompok saham dengan book-to-market rendah dan kelompok saham dengan kapitalisasi besar.

Keenam portofolio yang telah dibentuk hanya akan dipertahankan selama satu tahun, kemudian pada tahun berikutnya akan dibentuk enam portofolio yang baru berdasarkan pengelompokan size dan book-to-market value kembali pada data saham bulan desember tahun $\mathrm{t}-1$.

Return yang diharapkan dari suatu portofolio bisa diestimasi dengan menghitung rata-rata tertimbang dari return yang diharapakan dari masing-masing aset individu yang ada dalam portofolio. Perhitungan return dari portofolio yang telah dibentuk akan dihitung setiap bulan dalam satu tahun. Return bulanan dari setiap portofolio yang dibentuk dapat dihitung melalui persamaan berikut ini.

Di mana:

$$
E\left(R_{p t}\right)=\sum_{i=1}^{n} W_{i t} E\left(R_{i t}\right)
$$

$\mathrm{E}\left(\mathrm{R}_{\mathrm{pt}}\right)$ = return yang diharapkan dari portofolio pada bulan $\mathrm{t}$

$\mathrm{W}_{\mathrm{it}} \quad$ = bobot portofolio sekuritas ke-i pada periode $\mathrm{t}$ (dalam hal ini bulan $\mathrm{t}$ )

$\mathrm{E}\left(\mathrm{R}_{\mathrm{it}}\right) \quad$ = return yang diharapkan dari sekuritas ke-i untuk bulan $\mathrm{t}$

$\mathrm{N} \quad=$ jumlah sekuritas yang ada dalam portofolio.

Untuk $E\left(R_{i}\right)$ digunakan persamaan dengan menggunakan logaritma natural, seperti dibawah ini:

$$
E\left(R_{i t}\right)=\operatorname{Ln}\left[\frac{p_{i t}}{P_{i t-1}}\right]
$$


Di mana:

$E\left(R_{i t}\right) \quad=$ return yang diharapkan dari sekuritas untuk bulan $t$

$\mathrm{P}_{\mathrm{it}} \quad=$ harga saham $\mathrm{i}$ pada periode $\mathrm{t}$

$\mathrm{P}_{\mathrm{it}-1} \quad=$ harga saham $\mathrm{i}$ pada periode $\mathrm{t}-1$

Perhitungan dengan menggunakan logaritma natural juga dilakukan pada perhitungan tingkat keuntungan pasar (Rm),yaitu:

$$
R_{m t}=L n\left[\frac{P_{m t}}{P_{m t-1}}\right]
$$

Di mana:

$\mathrm{R}_{\mathrm{mt}} \quad=$ tingkat keuntungan pasar pada periode $\mathrm{t}$

$\mathrm{P}_{\mathrm{mt}} \quad$ = Indeks LQ45 pada periode $\mathrm{t}$

$\mathrm{P}_{\mathrm{mt}-1} \quad$ = Indeks LQ45 pada periode $\mathrm{t}-1$

Pada penelitian ini digunakan tiga model empiris. Model empiris pertama didasari dari CAPM, yaitu:

$$
\left(R_{p}\right)-R_{f}=a+\beta_{i}\left[(R M)-R_{f}\right]
$$

Model empiris kedua masih didasari oleh CAPM tetapi ditambah dengan satu variabel independen selain beta, yaitu size, yaitu:

$$
\left(R_{p}\right)-R_{f}=a+\beta_{i}\left(R M-R_{f}\right)+s_{i}(S M B)
$$

Model empiris ketiga adalah berdasarkan model Fama dan French (1995), yaitu:

$$
\left(R_{p}\right)-R_{f}=a+\beta_{i}\left(R M-R_{f}\right)+s_{i}(S M B)+h_{i}(H M L)
$$

Dimana:

$\mathrm{R}_{\mathrm{p}} \quad=$ Return Portofolio saham

$\mathrm{R}_{\mathrm{f}} \quad=$ risk free rate

$\mathrm{RM} \quad=$ return dari market portofolio

SMB = Small Minus Big, merupakan perbedaan antara equal-weight average of the return pada tiga portofolio saham kecil dan tiga portofolio saham besar. Hal ini dimaksudkan agar SMB bersih dari pengaruh rasio book-to-market

$\mathrm{HML}=$ High book to market minus low book to market, merupakan perbedaan antara return pada portofolio saham dengan book-to-market tinggi dan

\footnotetext{
${ }^{1}$ Model ini sesuai dengan model Michael E. Drew dan Madhu Veeraraghavan (Beta, Firm Size, Book-to-Market Equity and Stock Return) dalam Journal of the Asia Pacific Economy tahun 2003.
} 
return pada portofolio saham dengan boo-to-market rendah, disortir secara netral berdasarkan size.

$\beta_{\mathrm{i}} ; \mathrm{s}_{\mathrm{i}} ; \mathrm{h}_{\mathrm{i}} ;=$ factor loadings.

Pada penelitian ini akan dilakukan dua uji hipotesis. Pertama, pengujian hipotesis melalui uji regresi linier dengan melihat hasil koefisien determinasi, dan uji t. Kedua, pengujian hipotesis melalui uji regresi berganda yang meliputi uji t dan uji ANOVA atau uji F.

\section{Hasil dan Pembahasan}

Dari data yang diperoleh, maka dipilih seluruh sampel yang masuk dalam LQ45 pada satu periode. Kemudian sampel diranking berdasarkan size perusahaan dan book-tomarket value. Dalam perankingan berdasarkan Size semua sampel yang masuk dalam kriteria dibagi 2. Untuk tahun 2008 jumlah sample sebesar 56 saham. Sehingga dari perankingan tersebut akan didapat dua kelompok saham, yaitu kelompok saham kecil (small) dan kelompok saham besar (big) yang masing-masing berjumlah 28 saham. Sedangkan tahun 2009 jumlah sampel sebesar 52 saham, tahun 2010 jumlah sample sebesar 50 saham.

Jumlah sampel yang digunakan dalam pengelompokan book-to-market value sama dengan jumlah sampel yang digunakan dalam pengelompokan size, tetapi dalam pengelompokan book-to-market value di bagi ke dalam tiga kelompok. Untuk tahun 2008 kelompok saham yang masuk kategori BMV rendah sebanyak 16 saham, kelompok BMV menengah sebanyak 24 saham, dan kelompok BMV tinggi sebanyak 16 saham. Tahun 2009 jumlah saham mengalami penurunan, jumlah saham yang masuk kelompok BMV rendah sebanyak 16 saham, kelompok BMV menengah 21 saham, dan kelompok BMV tinggi sebanyak 16 saham. Dan untuk tahun 2010 sampel juga mengalami penurunan, jumlah saham yang masuk kelompok BMV rendah sebanyak 15 saham, kelompok BMV menengah 21 saham, dan kelompok BMV tinggi sebanyak 15 saham.

Setelah melakukan perankingan atas sample yang dipilih, maka akan dibentuk enam jenis portofolio sesuai dengan pengelompokan yang dilakukan Fama dan French (1995). Portofolio yang dibentuk dipertahankan selama satu tahun, dan dilakukan perhitungan return setiap bulannya. Jika dalam satu tahun pengamatan untuk perhitungan return ternyata ada saham yang tidak masuk dalam indeks LQ45 maka akan diganti dengan saham lain yang masuk dalam indeks LQ45, pengamatan dilakukan satu periode indeks, dan data akan diambil sesuai dengan periode masuknya saham dalam LQ45. 
Hasil perhitungan return market yang sudah dikurangi dengan risk free menggunakan data LQ45 bulanan dan SBI jangka waktu 1 bulan. Return market ini akan digunakan sebagai salah satu dari tiga variabel independen dalam model regresi, dua variabel independen lainnya adalah SMB dan HML.

Hasil pengujian kenormalan data yang dilakukan dengan menggunakan one-sample Kolmogorov Smirnov test terhadap enam portofolio yang telah dibentuk yaitu SL, SM, $\mathrm{SH}, \mathrm{BL}$, dan $\mathrm{BH}$ yang masing-masing akan dijadikan variabel dependen menunjukkan bahwa semua data terdistribusi normal yang ditunjukkan dengan nilai Asymp. Sig. (2tailed) sebesar 0,769 untuk variabel dependen SM, variabel SH ditunjukkan dengan nilai Asymp. Sig. (2-tailed) sebesar 0,898, variabel dependen BL ditunjukkan dengan nilai Asymp. Sig. (2-tailed) sebesar 0,996 variabel dependen BM yang ditunjukkan dengan nilai Asymp. Sig. (2-tailed) sebesar 0,878, serta variable dependen $\mathrm{BH}$ yang ditunjukkan dengan nilai Asymp. Sig. (2-tailed) sebesar 0,953.

Tabel 1. Hasil Uji Asumsi Klasik

\begin{tabular}{|l|c|c|c|}
\hline \multicolumn{1}{|c|}{ Uji Asumsi Klasik } & Model 1 & Model 2 & Model 3 \\
\hline Autokorelasi (DW) & 2,013 & 1,924 & 1,923 \\
\hline Multikolinieritas (VIF) & 1,000 & 1,019 & 1,045 \\
\hline Heteroskedastisitas (sig) & 1,000 & 1,000 & 1,000 \\
\hline
\end{tabular}

Dari tabel di atas menunjukkan hasil uji Autokorelasi dari seluruh model empiris terletak di antara nilai tabel du sebesar 1,6539 dan nilai dari 4 - 1,6539 (4-du), maka dapat disimpulkan bahwa data tersebut tidak terdapat autokorelasi. Hasil uji Multikolinieritas diketahui dari seluruh model empiris menunjukkan nilai VIF kurang dari 10, maka dapat disimpulkan bahwa antara variabel-variabel independen tidak terdapat gangguan multikolinearitas. Hasil Uji Heteroskedastisitas menunjukkan bahwa tidak ada satupun variabel independen yang signifikan mempengaruhi variabel dependen (absolute residual), sehingga dapat disimpulkan bahwa model regresi tidak mengalami masalah heteroskedastisitas.

Berdasarkan hasil regresi model empiris pertama (8) yang dilakukan dengan menggunakan program SPSS maka diperoleh hasil sebagai berikut : 
Tabel 2. Koefisien, $\mathrm{t}_{\text {hit, }} \mathrm{p}$-value dan adj. $\mathrm{R}^{2}$ dari Hasil Regresi Variabel Independen Market

\begin{tabular}{|c|l|c|c|c|}
\hline & & $\alpha$ & $\beta$ & Adj. $\mathrm{R}^{2}$ \\
\hline $\mathrm{SL}$ & Koefisien & 0,329 & 6,766 & 0,640 \\
\hline & $\mathrm{t}(\mathrm{p}$-value) & & $7,956(0,000)$ & \\
\hline $\mathrm{SM}$ & Koefisien & 0,318 & 6,841 & 0,630 \\
\hline & $\mathrm{t}$ (p-value) & & $7,779(0,000)$ & \\
\hline $\mathrm{SH}$ & Koefisien & 0,160 & 4,040 & 0,574 \\
\hline & $\mathrm{t}(\mathrm{p}$-value) & & $6,938(0,000)$ & \\
\hline $\mathrm{BL}$ & Koefisien & 0,348 & 4,928 & 0,748 \\
\hline & $\mathrm{t}(\mathrm{p}$-value) & & $10,238(0,000)$ & \\
\hline $\mathrm{BM}$ & Koefisien & 0,632 & 9,437 & 0,803 \\
\hline & $\mathrm{t}(\mathrm{p}$-value) & & $11,987(0,000)$ & \\
\hline BH & Koefisien & 0,557 & 8,261 & 0,722 \\
\hline & $\mathrm{t}(\mathrm{p}$-value $)$ & & $9,590(0,000)$ & \\
\hline
\end{tabular}

Dari hasil regresi yang dapat dilihat pada Tabel 3 di atas menunjukkan bahwa untuk semua variabel dependen, beta secara signifikan memiliki hubungan dengan return saham. Hal ini dikarenakan tingkat signifikansi jauh lebih kecil dari 0,05 (ditunjukkan pada $p$-value) dan juga didasari dari hasil uji t yang menunjukkan bahwa nilai $t_{\text {hit }}$ lebih besar dari $t$ tabel pada level signifikansi dibawah 0,05 . Nilai $t$ tabel dalam hal ini $<1,6896$. Jika dilihat dari nilai adjusted $\mathrm{R}^{2}$, maka dapat dikatakan model yang dibentuk pada saat menggunakan return portofolio SL sebagai variabel dependen mampu menerangkan variabel dependen sebesar $64 \%$, untuk dependen variabel portofolio SM sebesar $63 \%$, untuk portofolio SH sebesar $57,4 \%$, portofolio BL sebesar $74,8 \%$, portofolio BM sebesar $80,3 \%$ dan portofolio $\mathrm{BH}$ sebesar $72,2 \%$. Dan bisa dikatakan bahwa beta sangat berpengaruh terhadap return saham.

Hasil perhitungan model empiris kedua (9) ditunjukkan pada Tabel 3. Tabel menunjukkan regresi dengan menggunakan variabel independen beta dan size, diketahui bahwa nilai adjusted $\mathrm{R}^{2}$ model regresi ini hampir sama dengan nilai adjusted $\mathrm{R}^{2}$ pada model dengan menggunakan variabel beta sebagai satu-satunya variabel yang mempengaruhi return. 
Tabel 3. Koefisien, $t_{\text {hit, }} \mathrm{p}$-value dan adj. $\mathrm{R}^{2}$ dari Hasil Regresi Variabel Independen Market dan Size

\begin{tabular}{|c|c|c|c|c|c|}
\hline & & $\alpha$ & $\beta$ & $S$ & Adj. $R^{2}$ \\
\hline \multirow{2}{*}{ SL } & Koefisien & 0,369 & 6,916 & $0,190 *$ & 0,874 \\
\hline & t (p-value) & & $7,897(0,000)$ & $0,630 *(0,533)$ & \\
\hline \multirow{2}{*}{ SM } & Koefisien & 0,359 & 6,916 & $0,190 *$ & 0,623 \\
\hline & $\mathrm{t}$ (p-value) & & $7,718(0,000)$ & $0,613 *(0,544)$ & \\
\hline \multirow{2}{*}{ SH } & Koefisien & 0,239 & 4,188 & $0,376^{*}$ & 0,605 \\
\hline & t (p-value) & & $7,400(0,000)$ & $1,915 *(0,064)$ & \\
\hline \multirow{2}{*}{$\mathrm{BL}$} & Koefisien & 0,263 & 4,771 & $-0,398$ & 0,783 \\
\hline & t (p-value) & & $10,580(0,000)$ & $-2,546(0,016)$ & \\
\hline \multirow{2}{*}{ BM } & Koefisien & 0,556 & 9,296 & $-0,357 *$ & 0,807 \\
\hline & $\mathrm{t}$ (p-value) & & $11,819(0,000)$ & $-1,310 *(0,199)$ & \\
\hline \multirow{2}{*}{ BH } & Koefisien & 0,416 & 7,999 & $-0,664$ & 0,755 \\
\hline & t (p-value) & & $9,787(0,000)$ & $-2,343(0,025)$ & \\
\hline
\end{tabular}

Keterangan: * Tidak Signifikan

Jika didasari dari hasil uji $\mathrm{t}$, maka model yang menggunakan variabel dependen return portofolio $\mathrm{SL}, \mathrm{SM}, \mathrm{SH}, \mathrm{BL}, \mathrm{BM}$, dan $\mathrm{BH}$ menunjukkan bahwa secara individu faktor yang signifikan mempengaruhi return adalah beta. Sedangkan jika dilihat dari hasil uji $t$ pada variabel dependen portofolio $\mathrm{SL}, \mathrm{SM}, \mathrm{SH}$, dan $\mathrm{BM}$ size tidak berpengaruh terhadap return saham dan pada variabel dependen portofolio $\mathrm{BL}$ dan $\mathrm{BH}$ size secara signifikan berpengaruh negatif terhadap return saham.

Hasil perhitungan model empiris ketiga (10) ditunjukkan pada Tabel 4. Pada model yang menggunakan return portofolio $\mathrm{SL}, \mathrm{SM}, \mathrm{SH}, \mathrm{BL}, \mathrm{BM}$, dan $\mathrm{BH}$ sebagai variabel dependen, maka dapat diketahui bahwa secara individu variabel yang signifikan mempengaruhi return saham dalam portofolio adalah beta, hal ini dapat dilihat dalam tabel 4 pada nilai t untuk $\beta$ dan nilai t untuk $S$ yang memiliki nilai $t_{\text {hit }}$ yang lebih besar dari nilai $\mathrm{t}$ tabel yaitu 1,6896 . Sedangkan jika dilihat dari hasil uji t pada variabel dependen portofolio $\mathrm{SL}, \mathrm{SM}, \mathrm{SH}$, dan $\mathrm{BM}$ size tidak berpengaruh terhadap return saham. Dan pada variabel dependen portofolio $\mathrm{BL}$ dan $\mathrm{BH}$ size secara signifikan berpengaruh negatif terhadap return saham. Sedangkan untuk variabel independen book-to-market value dapat dikatakan tidak mempengaruhi return saham. 
Tabel 4. Koefisien, $t_{\text {hit, }} p$-value dan adj. $R^{2}$ dari Hasil Regresi Variabel Independen Market, Size dan Rasio Book-to-Market

\begin{tabular}{|c|c|c|c|c|c|c|}
\hline & & $\alpha$ & $\beta$ & S & $\mathrm{H}$ & Adj. $R^{2}$ \\
\hline \multirow[b]{2}{*}{ SL } & Koefisien & 0,370 & 6,854 & $0,194 *$ & $-0,114 *$ & 0,622 \\
\hline & t (p-value) & & $7,697(0,000)$ & $\begin{array}{l}0,627^{*} \\
(0,535)\end{array}$ & $\begin{array}{l}-0,092^{*} \\
(0,928)\end{array}$ & \\
\hline \multirow[b]{2}{*}{ SM } & Koefisien & 0,354 & 6,809 & $0,152 *$ & $0,968^{*}$ & 0,618 \\
\hline & $\mathrm{t}$ ( $\mathrm{p}$-value) & & $7,458(0,000)$ & $\begin{array}{l}0,480 * \\
(0,635)\end{array}$ & $\begin{array}{l}0,756^{*} \\
(0,455)\end{array}$ & \\
\hline \multirow[b]{2}{*}{$\mathrm{SH}$} & Koefisien & 0,236 & 4,107 & $0,347 *$ & $0,733^{*}$ & 0,603 \\
\hline & t (p-value) & & $7,150(0,000)$ & $\begin{array}{l}1,740 * \\
(0,092)\end{array}$ & $\begin{array}{l}0,910 * \\
(0,369)\end{array}$ & \\
\hline \multirow[b]{2}{*}{$\mathrm{BL}$} & Koefisien & 0,264 & 4,801 & $-0,388$ & $-0,267 *$ & 0,777 \\
\hline & t (p-value) & & $\begin{array}{l}10,384 \\
(0,000)\end{array}$ & $\begin{array}{l}-2,415 \\
(0,022)\end{array}$ & $\begin{array}{c}-0,413^{*} \\
(0,683)\end{array}$ & \\
\hline \multirow[b]{2}{*}{ BM } & Koefisien & 0,555 & 9,280 & $\begin{array}{c}- \\
0,363 *\end{array}$ & $0,141^{*}$ & 0,801 \\
\hline & t (p-value) & & $\begin{array}{l}11,481 \\
(0,000)\end{array}$ & $\begin{array}{c}- \\
1,293^{*} \\
(0,205)\end{array}$ & $\begin{array}{l}0,124 * \\
(0,902)\end{array}$ & \\
\hline \multirow[b]{2}{*}{$\mathrm{BH}$} & Koefisien & 0,410 & 7,868 & $-0,711$ & $1,188^{*}$ & 0,755 \\
\hline & t (p-value) & & $9,516(0,000)$ & $\begin{array}{l}-2,479 \\
(0,019)\end{array}$ & $\begin{array}{l}1,025^{*} \\
(0,313) \\
\end{array}$ & \\
\hline
\end{tabular}

Sumber: Hasil perhitungan SPSS 17.0 dan pengetikan pada excel Keterangan: * Tidak Signifikan

Pada semua variabel dependen return portofolio hanya beta yang berpengaruh positif terhadap return saham, baik pada pengujian individu maupun ketika di uji bersama dengan variabel size maupun book-to-market. Sehingga boleh dikatakan bahwa pada penelitian ini tidak menemukan adanya faktor selain beta yang berpengaruh terhadap return. Sehingga tujuan penelitian yang ingin membuktikan apakah ukuran perusahan, book-to-market value, dan beta dapat mempengaruhi return saham sesuai dengan penelitian Fama dan French tidak terbukti, hal ini terlihat dari tingkat signifikansi maupun t-tabel yang menunjukkan hanya beta yang secara individu dan signifikan mempengaruhi return saham di BEI. 
Hasil uji $\mathrm{F}$ pada model regresi yang menggunakan variabel independen beta, menunjukkan bahwa beta dapat mempengaruhi return saham pada semua variabel return portofolio dependen. Hal ini berdasarkan nilai uji $\mathrm{F}$ untuk return portofolio SL sebesar 63,294, SM sebesar 60,511, SH sebesar 48,139, BL sebesar 104,815, nilai uji F untuk return portofolio BM sebesar 143,687 dan BH sebesar 91,970. Sedangkan Nilai $F$ tabel dalam hal ini $<3,2674$ sehingga nilai $F_{\text {hit }}$ jauh lebih besar dari $F$ tabel.

Hasil uji $F$ pada model regresi yang menggunakan variabel independen beta dan size, nilai $\mathrm{F}_{\text {hit }}$ yang dihasilkan melalui uji $\mathrm{F}$ untuk model dengan return portofolio $\mathrm{SL}$ sebagai dependen variabel sebesar 31,285 , SM sebesar 29,887, SH sebesar 27,792, untuk BL sebesar 64,098 untuk BM sebesar 74,213 dan untuk BH sebesar 54,802. Sedangkan Nilai $F$ tabel dalam hal ini $<3,2674$ sehingga nilai $F_{\text {hit }}$ jauh lebih besar dari F tabel.

Pada model regresi dengan menggunakan variabel independen beta, dan size, dan rasio book-to-market nilai $\mathrm{F}_{\text {hit }}$ yang dihasilkan melalui uji $\mathrm{F}$ untuk model dengan return portofolio SL sebagai dependen variabel sebesar 20,233, SM sebesar 19,857, SH sebesar 18,708, untuk BL sebesar 41,714, untuk BM sebesar 48,005, dan untuk BH sebesar 36,941. Jika dibandingkan dengan nilai $F$ tabel dalam hal ini untuk setiap model dengan $\mathrm{df}$ untuk pembilang $=3$, dan $\mathrm{df}$ untuk penyebut $>35$, maka nilai $\mathrm{f}$ tabel $<3,2674$, sehingga dapat dikatakan semua variabel independen secara bersama mempengaruhi variabel dependen.

\section{Kesimpulan}

Berdasarkan penelitian yang telah diperoleh, maka dapat ditarik kesimpulan bahwa beta secara individu mempengaruhi return saham dalam semua portofolio yang di bentuk. Sedangkan beta dan size secara individu mempengaruhi return saham hanya dalam portofolio yang dibentuk berdasarkan kategori pengelompokan saham, yaitu kapitalisasi besar dengan book-to-market rendah, kapitalisasi besar dengan book-tomarket tinggi. Sedangkan beta, size, dan book-to-market value secara bersama-sama tidak mempengaruhi return saham pada semua variabel retur portofolio. Sehingga beta merupakan faktor yang paling kuat berpengaruh terhadap return saham di BEI.

Hasil penelitian ini berbeda dengan penelitian yang dilakukan Drew dan Madhu Veeraraghavan (2003). Hasil penelitian menemukan bahwa beta merupakan faktor yang paling kuat berpengaruh terhadap return saham di BEI. Penulis juga menyarankan untuk mengembangkan penelitian ini dengan melakukan penambahan variabel independen misalnya rasio E/B (Earning to Book Value), PSR (Price to Sales Ratio), rasio $\mathrm{P} / \mathrm{B}$, maupun rasio $\mathrm{PER}$. 


\section{Daftar Pustaka}

Asnawi, S. K, dan Wijaya, C. (2005) Riset Keuangan: Pengujian-pengujian Empiris. Jakarta: PT. Gramedia Pustaka Utama.

Banz, R.W, (1981) The Relation Between Return and Market Value Common Stocks, Journal of Financial Economics 9.

Brigham, E.F., and Houston, J.F., (2004) Fundamentals of Financial Management, ( $10^{\text {th }}$ edition). Ohio: A Division of Thomson Learning South-Western.

Connor, G., dan Sehgal, S. (2001) "Test of The Fama and French Model in India"

Daniel, K., and Titman, S., (1997) Evidence on The Characteristics of Cross-Sectional Variation in Stock Returns, Journal of Finance 52.

Drew, M.E, Naughton, T., and Veeraraghavan. (2003) Firm Size, Book-to-Market Equity and Security Returns : Evidence from The Shanghai Stock Exchange, Australian Journal of Management 28 (September), The Australian Graduate School of Management.

Drew, M.E., and Veeraraghavan, M. (2003) Beta, Firm Size, Book-to-Market Equity and Stock Return, Tailor and Franscis Ltd., Journal of The Asia Pasific Economy 8 (March).

Fama, E. F, and French, K. R. (1992) The Cross-section of Expected Stock Return, The Journal of Finance. Desember.

Fama, E. F, and French, K. R. (1995) Size and Book-to-Market Factors in Earnings and Return, the Journal of Finance, March.

Fama, E. F, and French, K. R. (1996) The CAPM is Wanted, Dead or Alive. the Journal of Finance, December.

Fama, E.F., and Mc Beth, J.D. (1973) Risk, Return and Equilibrium : Emperical Tests, Journal of Political Economy 81 (May-June).

Ghozali, I. (2009) Aplikasi Analisis Multivariate dengan Program SPSS. Semarang: Badan Penerbit Universitas Diponegoro

Hadad, M. D., Satrio W., dan Dwityapoetra S. B. (2004) Beta Sektor Sebagai Proxi Imbal Hasil dan Indikator Risiko di Pasar Saham. Jakarta: Direktorat Penelitian Dan Pengaturan Perbankan BI.

Husnan, S. (2003) Dasar-dasar Teori Portofolio dan Analisis Sekuritas (edisi ketiga). Yogyakarta: UPP AMP-YKPN.

Jagannathan, R., and McGrattan, E.R. (1995) The CAPM debate. Federal Reserve of Mincapolis Quarterly Review 19.

Jones, C.P. (2004) Investments: Analysis and Management (ninth edition). John Wiley and Sons, Inc. 
Kothari, S.P., Sanken, J., and Sloan, R.G. (1995) Another Look at The Cross Section of Expeted Stock Return, Journal of Finance 50 (March).

Miller, E.M., (1997), Risk, Uncertanty and Divergence of Opinion.

Pastor, L, and Stambaugh, R.F. (2000) Comparing Asset Pricing Models : an Invest Ment Perspective, Journal of Financial Economics 56.

Tandeliling, E. (2001) Analisis Investasi dan Manajemen Portofolio. Yogyakarta: BPFE. 